What is a good question asker better at? From unsystematic generalization to adult-like selectivity across childhood

\author{
Costanza De Simone $e^{1,2}$ and Azzurra Ruggeri ${ }^{1,2}$ \\ ${ }^{1}$ MPRG iSearch, Max Planck Institute for Human Development, Lentzealle 94, Berlin 14195, \\ Germany \\ ${ }^{2}$ School of Education, Technical University Munich, Marsstraße 20-22, 80335 Munich, Germany \\ Affiliation
}

Author Note

The authors have no conflict of interests to declare.

Correspondence should be addressed to Costanza De Simone, MPRS iSearch, Max Planck

Institute for Human Development, Lentzeallee, 94, 14195 Berlin, Germany. Email:

desimone@mpib-berlin.mpg.de (ORCID: 0000-0002-0239-7238). 


\begin{abstract}
Research suggests that children prefer to seek help from informants who demonstrate active-learning competence. What do children infer from the ability to ask informative questions? This project explores developmental changes in what 3- to 9-year-old children and adults $(N=$ 240) infer from informants' question-asking competence (Study 1a and b), and the extent to which they use such inferences to decide whom to learn from (Study 2). Results from Study 1a and $b$ suggest that adult-like meaningful inferences based on question-asking competence emerge around age 7. Correspondingly, in Study 2 we found that only older children and adults sought help on novel problems from a competent question asker, whereas all participants sought help from a knowledgeable informant when the problem was related to her domain of expertise. This project is a first step in understanding how children recognize people who are effective learners as reliable models to learn from.
\end{abstract}

Keywords: social learning, social cognition, cognitive development, question asking, selective trust 


\section{What is a good question asker better at? From unsystematic generalization to adult-like selectivity across childhood}

Children start grasping the complex laws of physics and the mechanics underlying causal relationships very early on, just by actively exploring and observing the environment around them. Infants quickly learn that when they throw an object, it falls, and that an object cannot go through a wall, no matter how hard you bang it against it. However, some other kinds of knowledge strongly depend and build on social interactions: How your parents met, that a certain object is called "ball," and that it is not nice to throw it in someone's face. Indeed, as soon as they start talking, children enlarge, deepen, enrich, and revise their knowledge about the physical and social world by asking an impressive number of (sometimes outlandish) questions: Why do people get tummy aches? Where do babies come from? How fast can a swordfish swim? From a very young age, children understand that questions are best answered by informants with relevant expertise, so that a fish expert is more likely to know the speed of a swordfish, whereas it would be best to ask a doctor to learn why people get tummy aches (Campos \& Stenberg, 1981; Chouinard, Harris, \& Maratsos, 2007; Lutz \& Keil, 2002; Meltzoff, 1990). However, in the real world, experts on fish, medicine, or anything else are not necessarily always available. In such situations, the best bet might be to ask someone who is resourceful, ingenious, and good at finding out things or solving problems. Do children make this inference? Do they think that good question askers are smarter, more knowledgeable, or better at solving problems and rely on them when relevant experts are not available? In this project, we explored across three experiments to what extent adults and 3- to 9-year-old children (a) generalize the ability to ask informative questions to abilities or characteristics (Study 1a and b) of varying degrees of relatedness and (b) use question-asking competence as a cue to assess informants' reliability as potential helpers on novel problems (Study 2).

\section{Children's Ability to Discriminate Between Informants}

Not all people are equally suited to answering children's questions, as individuals might lack the relevant knowledge or be deceitful. A significant body of literature has examined young children's 
strategies when discriminating between reliable and unreliable sources of information (see Mills, 2013, and Sobel \& Kushnir, 2013, for reviews). This research demonstrates that children's trust is driven by a complicated mixture of inferences drawn from the quality of the information provided (e.g., accuracy, completeness; see Jaswal, Croft, Setia, \& Cole, 2010; Koenig \& Jaswal, 2011; Pasquini, Corriveau, Koenig, \& Harris, 2007) and the characteristics of the agent providing the information (e.g., expertise, age, familiarity, culture; see Kinzler \& Spelke, 2011; Lutz \& Keil, 2002; VanderBorght \& Jaswal, 2009). Generally, results from these studies suggest that over the preschool years there are developmental improvements in how children understand the necessary characteristics of a reliable informant. For example, children younger than age 4 discounted claims made by informants who lacked relevant episodic knowledge (e.g., Robinson, Champion, \& Mitchell, 1999), who possessed negative characteristics (e.g., were mean; Mascaro \& Sperber, 2009), who expressed absolute uncertainty (e.g., Sabbagh \& Baldwin, 2001), and who showed a stable history of inaccuracy (Koenig \& Harris, 2005). Yet, only around age 6 do they take into account the degree of inaccuracy, the number of past errors, or even the deceptive intentions that an informant might demonstrate (e.g., Einav \& Robinson, 2010).

Most of the paradigms used to investigate selective trust focus on children's selection of informants. Only a few studies have examined the inferences children make about the presented informants, that is, the extent to which children attribute other positive (potentially irrelevant) characteristics to informants who have provided reliable information or demonstrated expertise. These studies have implemented several different paradigms: Some manipulated the informants' characteristics, such as gender (Ma \& Woolley, 2013), accent (Kinzler, Corriveau, \& Harris, 2011), attractiveness (Bascandziev \& Harris, 2016), physical disabilities (Jaffer \& Ma, 2015), or honesty (Li, Heyman, Xu, \& Lee, 2014), while others varied the type and quality of the information that the informants provided (e.g., claims referring to episodic or semantic knowledge, Esbensen, Taylor, \& Stoess, 1997; accurate or inaccurate labels of familiar objects, Brosseau-Liard \& Birch, 2011; Rakoczy, Warneken, \& Tomasello, 2009; Sobel \& Corriveau, 2010). Because of this diversity, and because very few of these studies have considered a broad 
developmental range, it is difficult to trace a clear developmental trajectory of children's inferences. Nonetheless, some researchers have suggested that the extent of children's generalizations depends on the kind of knowledge or expertise an informant exhibits or lacks (Mills, 2013). For instance, when an informant lacks situation-specific knowledge, children do not necessarily infer that that the informant also lacks semantic knowledge (Zmyj, Buttelmann, Carpenter, \& Daum, 2010). In contrast, when an informant exhibits semantic knowledge, children tend to make broader generalizations, for instance, about prosocial behavior or knowledge of words (Brosseau-Liard \& Birch, 2010), episodic information (e.g., an object's location; Palmquist \& Jaswal, 2015), or even about the informant's knowledge about the rules of a novel game (Rakoczy et al., 2009).

These differences in children's attributions of relevant knowledge might be related to the developmental improvements seen over the preschool years in children's ability to recognize that different individuals possess different kinds of knowledge or expertise. For instance, preschoolers ask their peers when they want to know how to play with a novel toy, but they turn to adults to find out about the nutritional value of foods (VanderBorght \& Jaswal, 2009). Three- to 5-year-olds think that doctors know more than car mechanics about how to fix a broken arm, whereas mechanics know more than doctors about how to fix a flat tire. Yet in the same study, 3-year-olds did not make the same judgment about topics that would lie within broader areas of expertise (e.g., who would know more about why plants need sunlight to grow or how to build a tree house), and without familiar experts as a base for attribution, 4- and 5-year-olds also failed to do so (Lutz \& Keil, 2002). Furthermore, although children as young as age 5 focus on the relevant clues when deciding whom to trust, at age 6 they still struggle to use this information to direct questions to the proper experts (Fitneva, Lam, \& Dunfield, 2013; Robinson, Butterfill, \& Nurmsoo, 2011). Similarly, although they can distinguish between knowable and unknowable pieces of information (e.g., the number of leaves on all the trees in the world), before age 7 , children still fail to use this information to discount an informant who very confidently claims to know unknowable things (Kominsky, Langthorne, \& Keil, 2016). 


\section{Children's Ability to Identify Efficient Learners and Effective Inquiries}

When seeking or endorsing information from other people in the real world, it is not always possible or easy to evaluate their expertise and therefore their reliability. In such scenarios, the safest and potentially most effective way to learn about the world may be to identify individuals who might be able to provide accurate and reliable information, regardless of their prior expertise, that is, good and effective learners. Indeed, recent work suggests that when making inferences about informants' reliability, young children do also consider how they have achieved their knowledge. For example, Einav and Robinson (2011) found that when presented with two accurate informants, 4- and 5-year-olds (but not 3-year-olds) were more likely to seek help about an unfamiliar animal's name from an aidless informant than from an informant who had always relied on help from a third party. Along these lines, a recent study found that preschoolers attributed problem-solving competence to informants who learned through independent, active exploration. In particular, when asked to figure out how to activate a novel toy, 3- to 7-year-old children preferred to seek help from an "active" learner-who had autonomously explored and figured out how to activate a novel toy-than from learners who were shown how to do so through passive observation or direct instructions. Interestingly, children's appreciation for the active learner's exploration competence emerged only when the problem to be solved was similar to the one the learner had previously solved. However, follow-up studies revealed that younger children's preference for an active learner may be guided by more superficial cues (e.g., the learner being alone while learning), rather then by a deeper appreciation or the exploration process (Bridgers, Gweon, Bretzke, \& Ruggeri, 2018). Recent work shows that preschoolers are also sensitive to inquiries' effectiveness. In particular, children select the most informative among given actions as early as age 3 (Ruggeri, Swaboda, Sim, \& Gopnik, 2019) and reliably identify the most informative of two questions from age 5 (Kachergis, Rhodes, \& Gureckis, 2017; Ruggeri, Sim, \& Xu, 2017). In this study, Ruggeri et al. (2017) presented preschoolers with a storybook describing the reasons why the monster Toma had been late for school over several days. In the Uniform condition, Toma had been late equally often for different reasons, whereas 
in the Skewed condition, Toma had been late for one particular reason more often (e.g., on 5 of 8 days he had been late because he had overslept). Children then learned that Toma was late yet again, and that two of his monster friends wanted to find out why. One of the friends asked a constraint-seeking question, reducing the space of hypotheses by targeting superordinate categories (e.g., "Was Toma late because he could not find something?") and the other asked a hypothesis-scanning question, which tested a hypothesis directly (e.g., "Was Toma late because he could not find his socks?"). Children were then asked to indicate which of Toma's friends would find out first why Toma had been late — that is, which friend asked the most informative question. Crucially, the constraint-seeking question was more effective in the Uniform condition, but the hypothesis-scanning question, targeting the most likely hypothesis, was more effective in the Skewed condition. In both conditions, most 5-year-olds selected the monster asking the most informative question, regardless of the question type. However, children's ability to adapt their question generation depending on the hypothesis space emerges only later, at around age 7 (e.g., Ruggeri \& Lombrozo, 2015; Ruggeri, Lombrozo, Griffiths, \& Xu, 2016), and continues developing until adulthood, in tandem with their developing mastery in formulating more abstract types of questions (e.g., constraint-seeking questions; Herwig, 1982; Legare, Mills, Souza, Plummer, \& Yasskin, 2013; Mosher, Hornsby, Bruner, \& Oliver, 1966; Ruggeri \& Feufel, 2015). Throughout this paper, we refer to the concept described above (and in research on question asking) as "effectiveness," that is, the ability to maximize the likelihood of finding out information or solving problems efficiently, by flexibly adapting different kind of questions to the characteristics of the task at hand.

\section{The Current Project}

In this project we investigated across three experiments the inferences people make based on other people's active-learning competence. In particular, we explored to what extent adults and 3to 9-year-old children generalize the ability to ask informative questions to other abilities and characteristics (Study 1a and b) of varying degrees of relatedness and use question-asking 
competence as a cue to infer other people's reliability as potential teachers on specific versus broader domains of knowledge (Study 2). One intriguing possibility is that children use the informativeness of other people's questions and strategies as a cue to assess their competence as potential informants. In this way, they can maximize the opportunity to acquire novel information regardless of the specific knowledge that an informant demonstrates.

\section{Study 1a}

The goal of this study was to obtain adults' judgments about how strongly question-asking competence relates to 12 different abilities, traits, and characteristics. On the one hand, we were interested in establishing if there are indeed selective, meaningful inferences to be draw from the quality of other people's inquiries. Specifically, we expected to demonstrate that adults deem some but not all of the abilities, traits, and characteristics to be related to question-asking competence, and to different extents. On the other hand, we used adults' judgments as a benchmark to evaluate when in childhood such adult-like meaningful intuitions begin to emerge and develop.

\section{Method}

Participants. Thirty adults ( 19 female; $M_{\text {age }}=28.09$ years; $\left.S D=7.63\right)$ participated in this study. All participants were recruited and tested at local museums in Berlin ${ }^{1}$. They were mostly white Europeans, native German speakers or fluent in German. Institutional Review Board (IRB) approval was obtained by the Max Planck Institute for Human Development in Berlin, and participants gave informed consent to participate in the study. One additional participant was excluded from the analyses because of missing data.

Design and procedure. Participants were tested individually in a secluded area of the museum. The procedure consisted of two phases: familiarization and test. ${ }^{2}$

\footnotetext{
${ }^{1}$ Museums in Berlin are particularly affordable and therefore accessible to people from a variety of economic backgrounds. Additionally, as we test in museums that offer appealing attractions for young kids, these are generally of broad interest to people from differing educational and social backgrounds.

${ }^{2}$ Please note that the procedures and experimenter scripts used in all studies are available on OSF: link.
} 
Familiarization phase. In the familiarization phase, participants were presented with a six-page storybook. The first page introduced two monsters, Bobo and Kila, that wanted to find out what had happened to their friend Toma on his first day of school and so they asked him some questions. The following four pages illustrated different episodes (scenarios) taking place on Toma's first day of school (e.g., Toma drew a surprise welcome gift from a bag), together with the questions that Bobo and Kila asked Toma to find out what happened (e.g., "Did you get a teddy bear?" or "Did you get a red toy car?"). On the bottom of the page, eight images, arranged in a row, illustrated the options that the monsters considered (the hypothesis space; e.g., "Bobo and Kila knew what was inside the bag"; see Figure 1). Across the four scenarios, one of the monsters (counterbalanced across participants) always asked informative questions, whereas the other always asked uninformative questions. The informative questions targeted half of the hypotheses considered, either by referring to a single hypothesis presented four times (hypothesis-scanning question; e.g., "Did you get a teddy bear?" when four of the eight objects in the gift bag were teddy bears; see Figure 1a), or by addressing a feature shared by four of the hypotheses (constraint-seeking question; e.g., "Did you get a round-shaped snack?" when four of the eight snacks in the bag were round; see Figure 1b). The uninformative questions targeted either an object that was not included in the hypothesis space (e.g., the red toy car; hypothesis-scanning question; see Figure 1a) or a feature shared by all the objects (e.g., something to eat; constraint-seeking question; see Figure 1b). A sixth page presented the two monsters again and summarized the lesson to be learned from the familiarization phase, reminding participants that "Bobo/Kila always asks good/bad questions, because they are very informative/not informative at all. She is a good/bad question asker!"

Test phase. In the test phase, participants were asked to complete a paper-and-pencil survey consisting of 12 questions that asked them to rate how much the 12 abilities, traits, or characteristics listed in Table 1 related to the ability to ask informative questions, as exemplified by the familiarization scenarios, on a scale of 0 (not related at all) to 10 (strongly related). Questions were presented in random order. As a memory check, at the end of the survey 


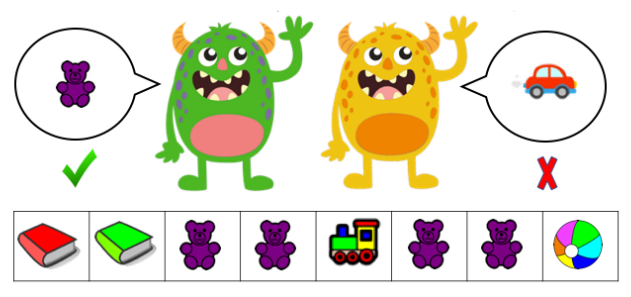

(a) Scenario 1. Hypothesis-scanning questions

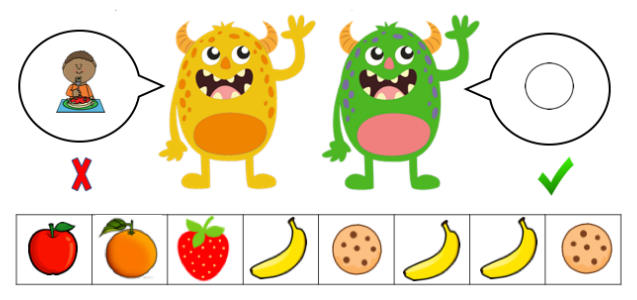

(b) Scenario 2. Constraint-seeking questions

Figure 1. Two different scenarios of the familiarization phase: Bobo, the green monster, asks informative questions that target either a single hypothesis (a: "Did you get a teddy bear?") or features shared by half of the hypotheses (b: "Did you get a round-shaped snack?"), whereas Kila, the yellow monster, asks uninformative questions that target either a hypothesis that is not part of the hypothesis space (a: "Did you get a toy car?") or a feature shared by all the hypotheses (b: "Did you get something to eat ?").

participants were asked to indicate again which monster was best at asking questions.

Given the exploratory nature of this study, the questions had been selected to cover a broad range of abilities, traits, and characteristics involving a stronger or weaker strategic component within different domains (i.e., physical and intellectual abilities and individual preferences). This is because we believed that both adults and children would have inferred that the better question asker was also the more efficient and strategic learner more generally and would have therefore based their judgments ("Would the question asker be better at this other skill, or more likely to have this trait?") on whether the skill/trait under consideration involved a similar strategic component. For instance, within the physical domain, we intuitively believed that "being better at playing soccer" would involve a stronger strategic component compared to "being able to see very far" and thus the former would be more likely to be associated with question-asking performance. However, these associations were pretty much speculative, and a small initial pilot among colleagues $(N=13)$ revealed great variance for some items. For this reason, and also taking into account the general lack of prior work we could use to ground a more objective classification, we adopted a bottom-up clustering approach to define the strength of the association of these abilities to question asking and used these results to estimate the meaningfulness of children's inferences in Study $1 \mathrm{~b}$. 
Table 1

Study 1a: Mean Adults' Ratings of the Strength of the Association Between Question-Asking Competence and 12 Abilities, Traits, and Characteristics.

\begin{tabular}{l|cc}
\hline Ability/trait/characteristic & $M$ & $S D$ \\
\hline Being good at school & 8.36 & 1.83 \\
Being smart & 8.30 & 1.91 \\
\hline Being good at treasure hunting & 6.76 & 2.21 \\
Being fast at jigsaw puzzles & 5.76 & 2.67 \\
\hline Knowing lots of animal names & 4.20 & 2.68 \\
Being friendly & 3.56 & 3.16 \\
\hline Having siblings & 2.13 & 2.53 \\
Being good at playing soccer & 1.63 & 2.08 \\
Seeing the farthest & 1.37 & 2.35 \\
Scoring lots of goals in soccer & 1.33 & 2.22 \\
Kicking a ball the farthest & 1.10 & 2.19 \\
Liking ice cream & 0.67 & 1.39 \\
\hline
\end{tabular}

Note. Horizontal lines delimit groups that according to hierarchical clustering results have the closest mean values.

\section{Results and Discussion}

All participants $(N=30)$ answered the memory check question correctly and were included in the analysis. ${ }^{3}$ We used a hierarchical clustering algorithm to assess how participants' ratings of the relatedness of question-asking competence to the 12 different abilities, traits, and characteristics clustered together. The similarity between ratings was calculated using the Minkowski distance measure (see Table A1). Clusters were created with the between-group average linkage method, which calculates the mean Minkowski distance between all possible intra- and intercluster object pairs and defines the clusters to minimize the average distance between the included objects. The optimal number of clusters to retain was determined with the "elbow criterion," that is, the point on a scree plot where the marginal gain of variance explained by the first clusters drops (see also Figures A1 and A2). If further examination of the cluster characteristics revealed no meaningful differences between two clusters, the clusters were combined. As a result, participants' ratings clustered across four dimensions, each including a subset of those traits, characteristics, and

\footnotetext{
${ }^{3}$ Please note that analysis scripts and data for all the studies are available on OSF: link.
} 
abilities sharing similar ratings (i.e., judged as similarly related to question-asking competence). Participants rated intellectual abilities such as being smart and being good at school as having a strong relation to the ability to ask informative questions $\left(n=2, M_{\text {rating }}=8.33\right)$. Abilities with a strategic component (i.e., being good at treasure hunting and being fast at completing jigsaw puzzles) were rated as having a moderately strong association with question-asking ability $(n=2$, $M_{\text {rating }}=6.26$ ). The associations with semantic knowledge (i.e., knowing lots of animal names) and being friendly were judged as moderately weak $\left(n=2, M_{\text {rating }}=3.88\right)$, although this latter social trait had the highest between-subjects variability (see Table 1). This seems to suggest that a person who is good at asking questions might be considered smart, sociable, or just generally more likely to interact with others and have more friends. Physical abilities, independent of whether they were more or less likely to involve a strategic component (being good at playing soccer vs. kicking a ball the farthest), individual preferences (e.g., liking ice cream), and irrelevant characteristics (e.g., seeing the farthest, having siblings) were clustered together and judged as not at all related to the ability to ask informative questions (weak: $n=6$, $\left.M_{\text {rating }}=1.37\right)$. Taken together, these results suggest that the adults made distinct, meaningful, and fairly consistent inferences and generalizations based on the ability to ask good questions. In Study $1 \mathrm{~b}$ we used a similar paradigm to explore to what extent such inferences and generalizations undergo a developmental change across childhood, and when adult-like intuitions might emerge.

\section{Study $1 \mathrm{~b}$}

\section{Method}

Participants. Participants were forty 3- to 4-year-old children (19 female; $M_{\text {age }}=48.41$ months; $S D=7.19$ ), forty 5 - to 6-year-olds (21 female; $M_{\text {age }}=70.18$ months; $S D=6.52$ ), and forty 7 - to 9 -year-olds ( 22 female; $M_{\text {age }}=101.59$ months; $S D=9.74$ ). Furthermore, since the procedure used in this study was likely to elicit a less explicit and "objective" association between question asking and a given ability, we deemed it necessary, for further comparisons, to have an additional adult sample tested with the children's procedure. Therefore, 40 adults ( 25 female; 
$M_{\text {age }}=34.56$ years; $S D=10.60$ ) also participated in this study.

A statistical power analysis was performed to estimate sample size, based on the probability of an event occurring above chance level (>50\% binomial tests). The projected sample size needed to detect a large effect size $(g=0.25)$ with $\alpha=.04$ and power $(1-\beta=.85)$ was approximately $N=$ 35 (lower critical $N=11$; upper critical $N=24) .{ }^{4}$ Moreover, some findings suggest using a sample size of 30 as a lower bound for large-sample inference for binary data (Agresti \& Min, 2002). Thus, our proposed sample size of $N=40$ per age group is more than adequate.

Participants were recruited and tested at local museums in Berlin. They were mostly white Europeans from diverse social classes and were native German speakers or fluent in German. IRB approval was obtained by the Max Planck Institute for Human Development in Berlin, and all participants (and participants' parents) gave informed consent to participate before the study. Twenty-four additional participants were excluded from the analyses because of technical issues $(n=2)$ or for failing the attention check $(n=7)$, the memory check $(n=9)$, or both $(n=6$; see below).

Design and procedure. The design and procedure of Study $1 \mathrm{~b}$ were identical to those in Study 1a, with the following exceptions: First, the task was implemented on a 10-inch tablet, and the script was read aloud to participants by an experimenter, who also reminded them, at the end of each scenario, which monster was a "good" and which one a "bad" question asker. Second, instead of being asked to rate the strength of the association between the given abilities, traits, and characteristics and question-asking effectiveness as in Study 1a, participants were asked to select the one monster they thought was more likely to possess or was better at the presented abilities, traits, and characteristics. Two cards illustrating the monsters were used to help participants indicate their selection. Finally, participants were asked both at the beginning (attention check) and at the end (memory check) of the test phase to indicate which monster was best at asking questions.

\footnotetext{
${ }^{4}$ Power analyses were performed using G*Power V3.1.9.6 (Faul, Erdfelder, Lang, \& Buchner, 2007).
} 


\section{Results}

Did participants' attributions of abilities, traits, and characteristics reflect their relatedness to question-asking competence? Participants' selections were coded as " 1 " when they indicated the monster that asked informative questions or " 0 " when they indicated the monster that asked uninformative questions. We fit a mixed-effects logistic regression model predicting participants' selection in this study (informative vs. uninformative question asker) with fixed effects of age (continuous) and mean ratings (continuous) of the strength of the association between question-asking competence and the 12 abilities, traits, and characteristics (obtained in Study 1a), and their interaction, including a random intercept for subject. ${ }^{5}$ The model revealed that the strength of the relatedness between question-asking competence and the different abilities, traits, and characteristics significantly predicted participants' choices in this study $(\beta=0.29, S E=0.09, z=5.53, p<.01)$. Furthermore, whereas this model revealed that age did not have a main effect $(\beta=-0.13, S E=0.07, z=-1.83, p=.07)$, it showed a positive interaction between participants' age and the mean association's strength $(\beta=0.11, S E=0.05$, $z=2.11, p=.04)$. To further examine this interaction, we fit the same logistic regression models for each age group separately. These models showed that the association strength was reflected only in the selections of adults $(\beta=0.39, S E=0.10, z=3.98, p<.001)$ and 5 - to 9-year-olds (5to 6-year-olds: $\beta=0.30, S E=0.12, z=2.60, p=.01$; 7 - to 9-year-olds: $\beta=0.36, S E=0.11$, $z=3.32, p<.001)$ and not in those made by 3 - to 4-year-old children $(\beta=0.13, S E=0.10$, $z=1.28, p=.20$; see also Figure 2).

\section{To what extent did participants attribute each trait, ability, and characteristic to the} question askers? We performed a two-way repeated measures analysis of variance to assess whether the extent of participants' attributions of traits, characteristics, and abilities to the question askers differed across clusters (i.e., resulting from Study 1a) and interacted with age (dummy coded as a factor with eight levels: 3- to 9 and 18). The analysis revealed that the clustered traits, abilities, and characteristics had a significant effect on participants'selections,

\footnotetext{
${ }^{5}$ All Generalized Linear Mixed-Effects Regression Models were run using the lme4 package, version v1.1-23.
} 


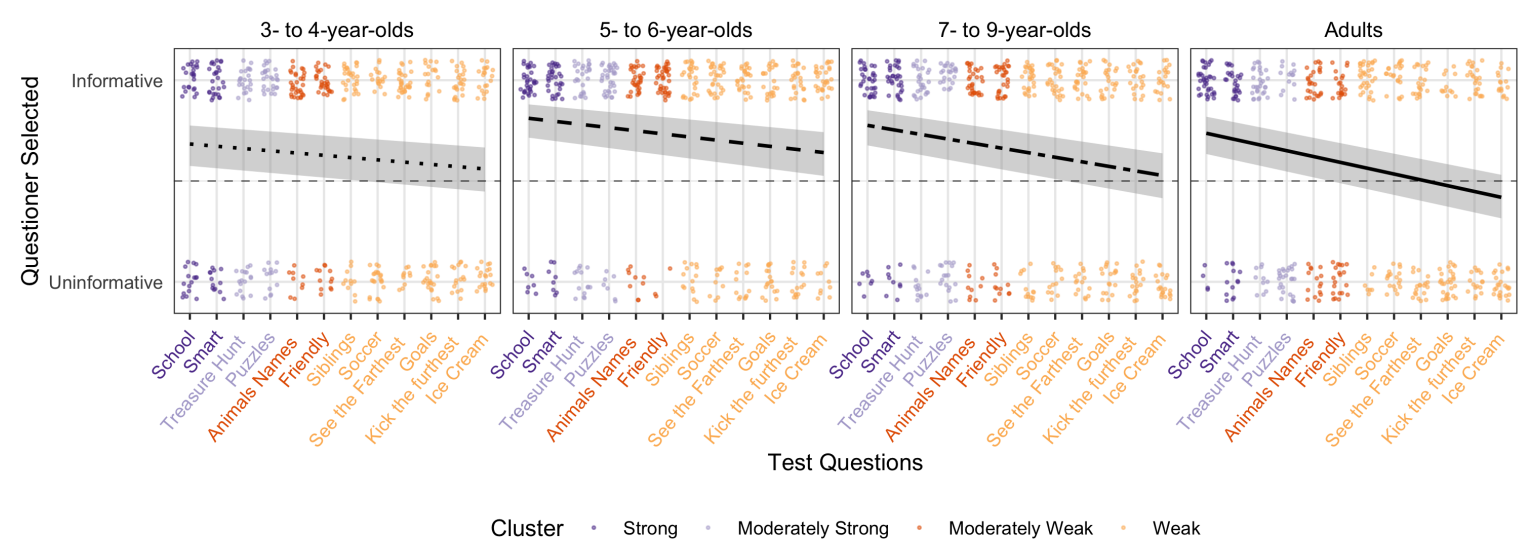

Figure 2. Study 1b: Participants' questioner choice by age group on each of the 12 abilities, traits, and characteristics, arranged in descending order (from strongest to weakest), and color coded according to the strength of their association with question asking, as indicated by the independent adult sample in Study 1a. Dashed horizontal lines represent chance level (50\%). The gray areas represent $95 \%$ bootstrapped confidence intervals.

$F(3,160)=7.16, p<.001$, and interacted with age almost significantly, $F(21,160)=1.49$, $p=.07$. To follow up on these developmental differences, we fit a series of mixed-effects logistic regression models predicting participants' choice on each cluster separately, with a fixed effect of age group (factor with three levels and adults' choices as baseline) and with a random intercept for subject. These models, in combination with a series of binomial tests (reported in Table 2), were run to assess the consistency with which participants of different age groups associated question-asking competence with abilities, traits, and characteristics of varying degrees of relatedness, and the extent to which their attributions were above chance level. In particular, as illustrated in Figure 2, the 3- to 4-year-olds were generally conservative in the extent of their generalizations (only $25 \%$ of attributions were above chance level) ${ }^{6}$ but also unsystematic with respect to the actual relatedness of the abilities to question-asking competence provided by adults in this study and in the pilot. Indeed, logistic regression models revealed that this was the only age group in which the children, when compared to adults in this study, were less likely to base their choice of the question asker on the characteristics rated as strongly related to

\footnotetext{
${ }^{6}$ The significance level for all binomial tests against chance $(50 \%)$ was set to $g=0.25(\bar{X}>.75)$ and $\alpha=.01$ to adjust to the power analysis' results.
} 
question-asking competence $(\beta=-0.86, S E=0.44, z=-1.95, p=.05)$. Along these lines, similarly to other children, they were also more likely than adults to generalize question-asking ability to characteristics with a moderately weak association $(\beta=0.78, S E=0.34, z=2.30$, $p=.02$ ). Five- to 6-year-olds deemed question-asking competence to be related to most of the abilities, traits, and characteristics (58\%), regardless of their actual relevance to question-asking competence. In fact, they were more likely than adults to attribute to the question asker those abilities whose relatedness to question asking was judged as moderately strong $(\beta=0.96$, $S E=0.42, z=2.30, p=.02)$, moderately weak $(\beta=1.48, S E=0.39, z=-3.84, p<.001)$, and weak $(\beta=0.60, S E=0.25, z=-2.46, p=.01)$. Seven- to 9-year-old children made more selective attributions at above chance level (33\%), generalizing question-asking competence to all the strongly related intellectual traits and abilities, but also to some abilities that had a moderately weak association with question asking to a significantly greater extent than adults $(\beta=0.78$,

$S E=0.34, z=2.30, p=.02$; see also Table A2 to see the models conducted on questions and not clusters).

Table 2

Study 1b: Mean Proportion of Participants Who Indicated the Best Question Asker as More Likely to Possess Each Ability, Trait, and Characteristic

\begin{tabular}{c|ccc|cccc|ccc|cc}
\hline Ability/trait/characteristic & \multicolumn{3}{|c|}{ 3- to 4-year-olds } & \multicolumn{3}{|c|}{ 5- to 6-year-olds } & \multicolumn{3}{c|}{ 7-to 9-year-olds } & \multicolumn{2}{c}{ Adults } \\
\cline { 2 - 13 } & $M$ & $95 \%$ CI & $p$ & $M$ & $95 \%$ CI & $p$ & $M$ & $95 \%$ CI & $p$ & $M$ & $95 \%$ CI & $p$ \\
\hline Being good at school & .60 & {$[0.43,0.75]$} & .27 & .83 & {$[0.67,0.92]$} & $<.001$ & .83 & $0.67-0.92$ & $<.001$ & .90 & {$[0.76,0.97]$} & $<.001$ \\
Being smart & .68 & {$[0.50,0.81]$} & .04 & .80 & {$[0.64,0.90]$} & $<.001$ & .78 & $0.61-0.89$ & $<.001$ & .68 & {$[0.51,0.81]$} & .04 \\
\hline Being good at treasure hunting & .58 & {$[0.48,0.73]$} & .43 & .65 & {$[0.48,0.79]$} & .08 & .68 & $0.50-0.81$ & .04 & .75 & {$[0.59,0.87]$} & $<.001$ \\
Being fast at jigsaw puzzles & .68 & {$[0.50,0.81]$} & .04 & .83 & {$[0.67,0.93]$} & $<.001$ & .58 & $0.40-0.73$ & .43 & .35 & {$[0.21,0.52]$} & .08 \\
\hline Knowing lots of animal names & .78 & {$[0.61,0.89]$} & $<.001$ & .78 & {$[0.61,0.89]$} & $<.001$ & .75 & $0.58-0.87$ & $<.001$ & .63 & {$[0.46,0.77]$} & .15 \\
Being friendly & .70 & {$[0.53,0.83]$} & .02 & .93 & {$[0.80,0.98]$} & $<.001$ & .73 & $0.56-0.85$ & .01 & .50 & {$[0.34,0.66]$} & 1 \\
\hline Having siblings & .73 & {$[0.56,0.85]$} & .01 & .65 & {$[0.48,0.79]$} & .08 & .68 & $0.50-0.81$ & .04 & .83 & {$[0.67,0.93]$} & $<.001$ \\
Being good at playing soccer & .45 & {$[0.29,0.62]$} & .64 & .75 & {$[0.59,0.87]$} & $<.001$ & .68 & $0.50-0.81$ & .04 & .55 & {$[0.38,0.71]$} & .64 \\
Seeing the farthest & .75 & {$[0.58,0.86]$} & $<.001$ & .68 & {$[0.50,0.81]$} & .04 & .63 & $0.45-0.77$ & .15 & .53 & {$[0.36,0.68]$} & .87 \\
Scoring lots of goals in soccer & .45 & {$[0.29,0.62]$} & .64 & .55 & {$[0.39,0.71]$} & .64 & .55 & $0.38-0.70$ & .64 & .30 & {$[0.17,0.47]$} & .02 \\
Kicking a ball the farthest & .60 & {$[0.43,0.75]$} & .27 & .60 & {$[0.43,0.75]$} & .27 & .55 & $0.38-0.70$ & .64 & .60 & {$[0.43,0.75]$} & .27 \\
Liking ice cream & .50 & {$[0.33,0.66]$} & 1 & .75 & {$[0.58,0.87]$} & $<.001$ & .50 & $0.33-0.66$ & 1 & .40 & {$[0.25,0.57]$} & .27 \\
\hline
\end{tabular}

Note. $P$ values refer to binomial tests against chance level $(50 \%) . \mathrm{CI}=$ confidence interval. Horizontal lines delimit groups that according to hierarchical clustering results have the closest mean values.

Taken together, our results suggest that the attributions made by 5- to 9-year-old children and adults (but not 3- to 4-year-olds) reflected the strength of the association between question-asking competence and relevant abilities, traits, and characteristics provided by an independent adult 
sample in Study 1b. However, the extent of participants' generalizations on each of these skills underwent an interesting developmental trend. Three- to 4-year-olds drew unsystematic inferences from the monsters' question-asking competence, showing no preference for the good question asker when evaluating abilities, traits, and characteristics that both adults and older children deemed strongly related to question asking (i.e., "being good at school," "being smart," "being good at treasure hunting"). At the same time, they showed a strong preference for the competent question asker on some weakly related abilities, such as seeing the farthest, and characteristics related to the social character of the question asker, such as being friendly or having siblings.

Five- to 6-year-olds identified the good question asker as being more likely to have $58 \%$ of the presented abilities, traits, and characteristics, suggesting that they considered effective question asking an indicator of global expertise and general likability. One can speculate that this stage of development may represent a stepping stone to a more fine-grained mastery of active learning skills and to more selective inferences that emerge later in development. In this respect, our results suggest that starting from around age 7, children showed adult-like response patterns, selectively associating question-asking competence with only $33 \%$ of the (most relevant) abilities, traits, and characteristics and not others. However, while in many studies focusing on generalizations, two informants are presented as experts in different domains (e.g., Jaswal et al., 2010; Koenig, 2012; Kushnir, Vredenburgh, \& Schneider, 2013; Lutz \& Keil, 2002), in our studies, the good question asker was contrasted with a bad question asker, to whom no other positive or neutral features were attributed. In this scenario, children may fall prey to a sort of halo effect: They may attribute all characteristics to the one informant who was presented with a positive feature only to avoid the bad one. This trend was particularly evident in 5- to 6-year-old children. To address this limitation, in Study 2 we pitted an effective question asker against a knowledgeable informant to assess to whom children turn when they have to answer a trivia question. When is it more important to know things and when to know how to find out things? This contrast is particularly interesting because results from Study $1 \mathrm{~b}$ suggest that all children 
believe that being good at asking questions also implies being more knowledgeable.

\section{Study 2}

\section{Method}

Participants. Pilot testing strongly indicated that the paradigm developed for Study 2 was too demanding for 3- to 4-year-olds, of whom more than half $(n=14,69 \%)$ failed both the attention and the memory check (see Design and procedure section below). We therefore decided to discontinue testing this age group. Participants included in the analysis were twenty-three 5- to 6-year-old children ( 7 female; $M_{\text {age }}=74.71$ months; $S D=6.63$ ), thirty-seven 7 - to 9-year-old children $\left(16\right.$ female; $M_{\text {age }}=102.69$ months; $\left.S D=10.94\right)$, and 20 adults $\left(11\right.$ female; $M_{\text {age }}=34.50$ years; $S D=12.27$ ), recruited and tested at a local museum in Berlin. They were mostly white Europeans from diverse social classes and were native German speakers or fluent in German. IRB approval was obtained by the Max Planck Institute for Human Development in Berlin, and all participants (and participants' parents) gave informed consent to participate before the study. An additional 27 participants were excluded from the analysis for failing the memory check (three 5to 6-year-olds, one 7- to 9-year-old) or both the attention and the memory check (thirteen 5- to 6-year-olds, three 7- to 9-year-olds, three adults), for quitting the session prematurely (one 5- to 6-year-old), for having a learning disability (one 7- to 9-year-old) or an intellectual disability (one adult), or for technical issues (one adult).

Design and procedure. Participants were tested individually in a secluded area of the museum. The procedure consisted of three phases, all implemented on a 10-inch tablet.

Familiarization phase. During the familiarization phase, participants were presented with two informants: One was really good at finding out things by asking informative questions (the question asker) but did not know anything about fish; the other one was knowledgeable about fish (the fish expert) but always asked uninformative questions. Four videos were used to introduce the two female informants (one at a time) who could be distinguished only by the color of their shirt (blue or yellow; counterbalanced order). The videos captured the informants from the back 
while they were sitting at a desk (see Figure $3 a$ and $3 b$ ), facing an image projected onto a wall. In two of the four videos, a third neutral agent pointed at the images of eight fish on the wall and asked each informant separately "Which one is fastest?" In one video the question asker replies by asking three constraint-seeking questions, each ruling out half of the options left under consideration and therefore maximally informative (i.e., "Is the fastest fish long?" when there were eight fish and just four of them had an oblong shape, "Is the fastest fish silver?" when two of the four remaining fish were silver and the other two were blue and yellow, and "Is the fastest fish the one with the long nose?" when there were only two options left, consisting of one blue fish with a long nose, the target, and one yellow fish. In the other video the fish expert replies by expressing her expertise about the topic (e.g., "I know which one is the fastest. It's the one with the long nose, the black marlin! It's very big and can swim at $129 \mathrm{~km} / \mathrm{h}$.”), without the need to ask any questions. In the remaining two videos, both informants were questioned about a neutral topic (unrelated to the informants' expertise). The third neutral agent pointed at the images of eight exotic fruits on a wall and asked: "Which one comes from Mexico?" Again, in one video the question asker identified the answer by asking three maximally informative constraint-seeking questions (i.e., "Is it yellow?" when four of the eight fruits presented were yellow, two were red, and two were pink, "Is it smooth?" when two of the four remaining fruits had a smooth shiny peel and the other two were covered with thorns, and "Is it the pink one?" when the two remaining options were a red and a pink fruit). In the other video, the fish expert asked three

hypothesis-scanning questions, each ruling out only one hypothesis at each step (i.e., "Is it the one that looks like a lemon?" then "Is it the one that looks like a melon?" and finally "Is it the pink one?" targeting the right fruit but when there were still five open unexplored options). Animations were used to cover the options that were ruled out (and highlight the ones that were still open), as well as to highlight the target at the end. In all videos both informants eventually identified the target fish and fruit. However, the process they used to find the answer differed according to the domain of knowledge each question targeted. The question asker found out by asking effective questions in two domains she did not have knowledge of (fish and fruit). The fish expert went 
straight to the solution when she was questioned about her domain of expertise (fish) and guessed the right solution by asking ineffective questions when she was questioned about a domain that was unrelated to her knowledge (fruit).
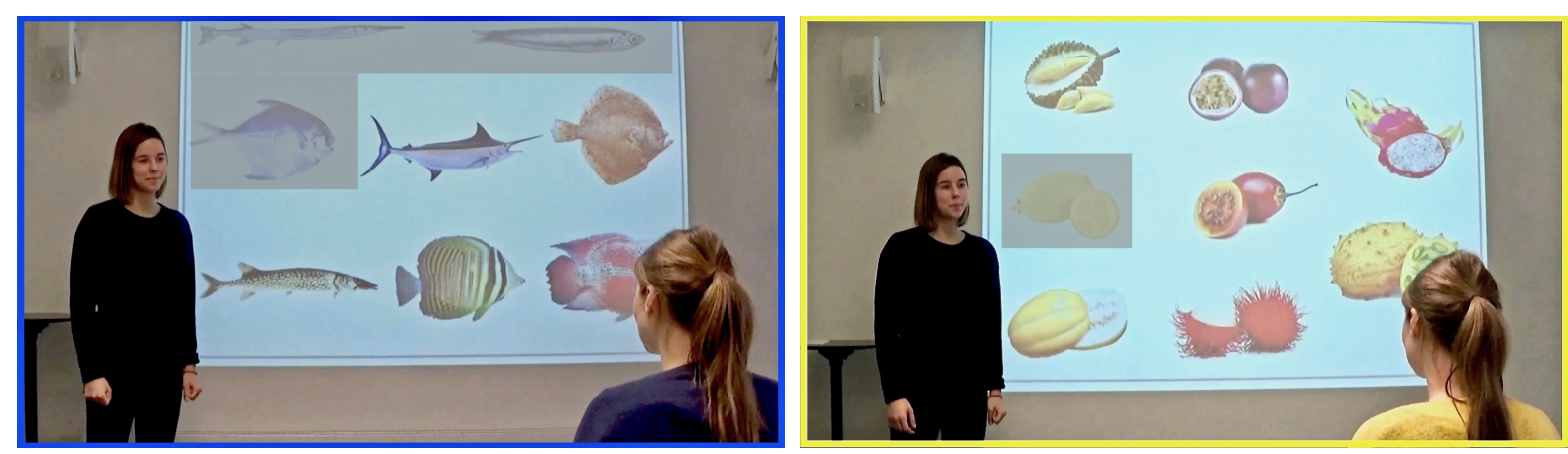

(a) Question asker asks a constraint-seeking question (b) Fish expert asks a hypothesis-scanning question

Figure 3. The two scenarios of the familiarization phase.

First test. In the first test phase, participants were asked three quiz questions, presented in random order, related to the expert's domain of expertise in different ways: One of the questions referred to fish (same-domain question: "Do you know which of these fish can fly?"); one referred to a related domain (animals; related-domain question: "Do you know which of these animals is the pangolin?"); and one referred to an unrelated domain (houses; unrelated-domain question: "Do you know which of these houses is in Germany?"). For each question, the options to be considered were presented in a $3 x 4$ grid (see Figure 4). Two colored frames (blue and yellow, positions counterbalanced across trials) placed below the grid were used to illustrate the two informants to be selected. As expected, most participants did not know the answer to any of the questions. In this case, the experimenter suggested asking one of the informants for help (i.e., “Hmmm, I don't know this either, but we can ask one of my friends for help. Whom do you want to ask?"). Participants were not given any feedback until all questions had been asked. In a few cases participants knew the answers already (fish: two adults, two 7- to 9-year-olds, five 5- to 6-year-olds; animals: one adult, one 7- to 9-year-old; houses: six 7- to 9-year-olds, eight 5- to 6-year-olds). These participants were asked to indicate which of the two informants they would have asked for help if they had not known the answer. Both at the beginning (attention check) and 
at the end (memory check) of the test phase, we also asked participants to indicate which informant was good at asking questions and which was a fish expert, but also which one was not good at asking questions and which one was not a fish expert.

Second test. In a second test phase, participants were asked to indicate which of the two informants was more likely to possess or be good at some of the abilities, traits, and characteristics presented to participants in Study 1a and b. In particular, we selected "being good at treasure hunting," an ability that was rated by both children and adults (Study 1 and pilot) as strongly related to question-asking competence; "knowing lots of animal names," to examine whether participants would attribute more factual knowledge to the good question asker (as they did in the previous studies) when contrasted to someone knowledgeable in a related domain; and "being smart," to explore whether participants would be more likely to relate intelligence to knowledgeability or effectiveness in search; and finally, "liking ice cream," as a control question. At the end of the session, participants were given the solutions to the quiz questions presented earlier.

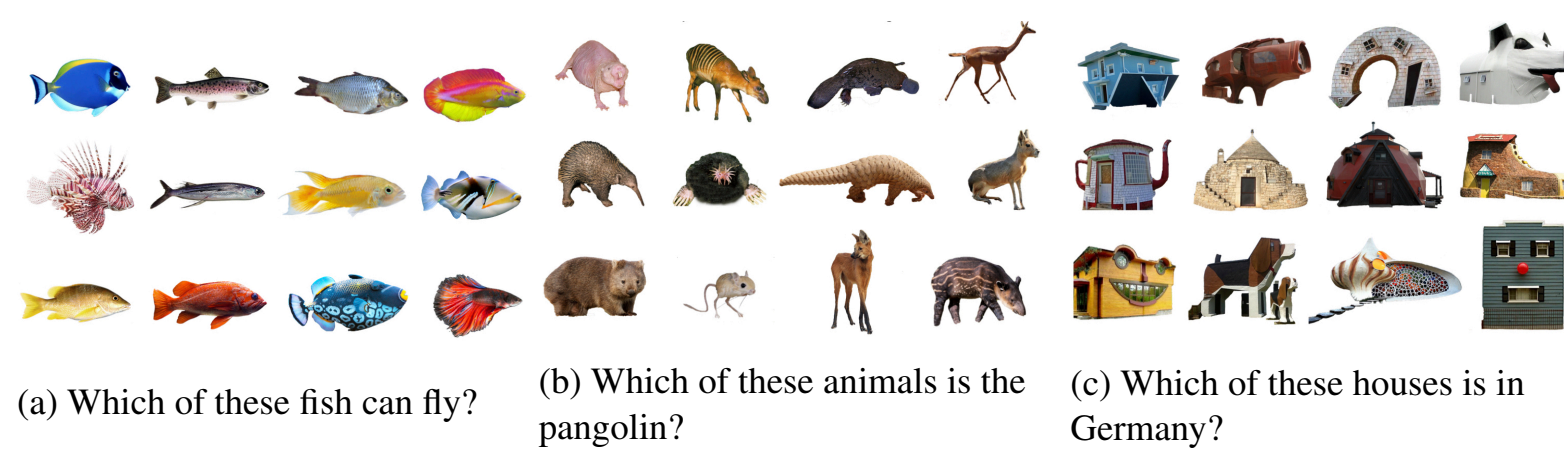

Figure 4. Stimuli used for the quiz questions, varying in how much the topic related to the domain of expertise (fish) of the expert: (a) same domain, (b) related domain, and (c) unrelated domain.

\section{Results and Discussion}

Whom did participants ask for help? Participants' selections were coded as "1" when they indicated the question-asking expert and as " 0 " when they indicated the fish expert. To assess developmental differences, we fit a mixed-effects logistic regression model predicting 
participants' informant selection on each quiz question separately, with fixed effects of age (continuous). The models show that participants' age had a significant effect on the likelihood of choosing the question asker for help on the quiz questions targeting the related domain (animals: $\beta=5.71, S E=4.75, z=2.14, p=.03$ ), marginally significant in the unrelated domain (houses: $\beta=2.45, S E=1.20, z=1.77, p=.07$ ), but no effect in the same domain (fish: $\beta=0.83$, $S E=0.25, z=-0.63, p=.53)$, where-as confirmed by binomial tests against chance $(50 \%)$-both adults and children preferred the fish expert (5- to 6-year-olds: $73.9 \%, p=.03 ; 7$ - to 9-year-olds: $77.8 \%, p<.001$; adults: $80 \%, p=.01$ ). We used a Wilcoxon rank-sum test to compare participants' selections on the related and unrelated domains across age groups (see also Table A3 for logistic regression). As illustrated in Figure 5, both adults and 7- to 9-year-olds were significantly more likely than 5- to 6-year-olds to ask the question asker for help in the related (7to 9-year-olds: $Z=-2.18, p=.02$; adults: $Z=-3.55, p<.001$ ) and unrelated (7- to 9-year-olds: $Z$ $=-2.03, p=.04$; adults: $Z=-2.66, p<.01)$ domains. Furthermore, adults preferred the question asker to a greater extent than 7- to 9-year-olds when they had to ask for help in the related domain, $Z=-2.03, p=.04$, but not in the unrelated domain, $Z=-1.13, p<.25$. Indeed, for the related-domain question, both 7- to 9-year-old children and adults preferred to ask the question asker for help (7- to 9-year-olds: $72.2 \%, p=.01$; adults: $95 \%, p<.001$ ), whereas 5 - to 6-year-olds' selections did not differ from chance $(p=.67 ; 43.5 \%)$. Similarly, for the unrelated-domain question, both adults and 7- to 9-year-old children preferred the question asker (7- to 9-year-olds: $77.8 \%, p<.001$; adults: $90 \%, p<.001$ ), but again, 5 - to 6-year-olds' selections did not differ from chance $(52.2 \%, p=1)$.

Summarizing, our results are in line with previous literature suggesting that even 3-year-old children impose epistemic boundaries on what they assume an expert knows (e.g., Lutz \& Keil, 2002; VanderBorght \& Jaswal, 2009). In this study, both younger and older children, like adults, preferred to team up with someone possessing specific factual knowledge (i.e., the fish expert) when this knowledge was relevant to the domain of knowledge they wanted to learn about. On the 
other hand, only older children and adults perceived someone who is good at finding out things as a better informant to learn about more generic domains of knowledge, such as animals or houses. Indeed, although 5- to 6-year-olds showed a clear preference for the fish expert when they had to learn about the domain that was related to her expertise, they did not attribute broader generic knowledge to either the fish expert or the question asker. This result confirms previous results suggesting that children in this age group still fail to attribute knowledge to unfamiliar experts when this would lie within (broader) areas of their expertise (e.g., Aguiar, Stoess, \& Taylor, 2012; Lutz \& Keil, 2002; Robinson et al., 2011). In this sense, this might indicate that advanced active learning abilities might be required to perceive a good question asker as a reliable source of information and to understand that sometimes being a good learner or problem solver might be more useful than being knowledgeable. Nevertheless, we should also mention that the subtle manipulation of the informants' characteristics in Study 2 might have been challenging to grasp for younger children. Indeed, many of them failed the memory check.
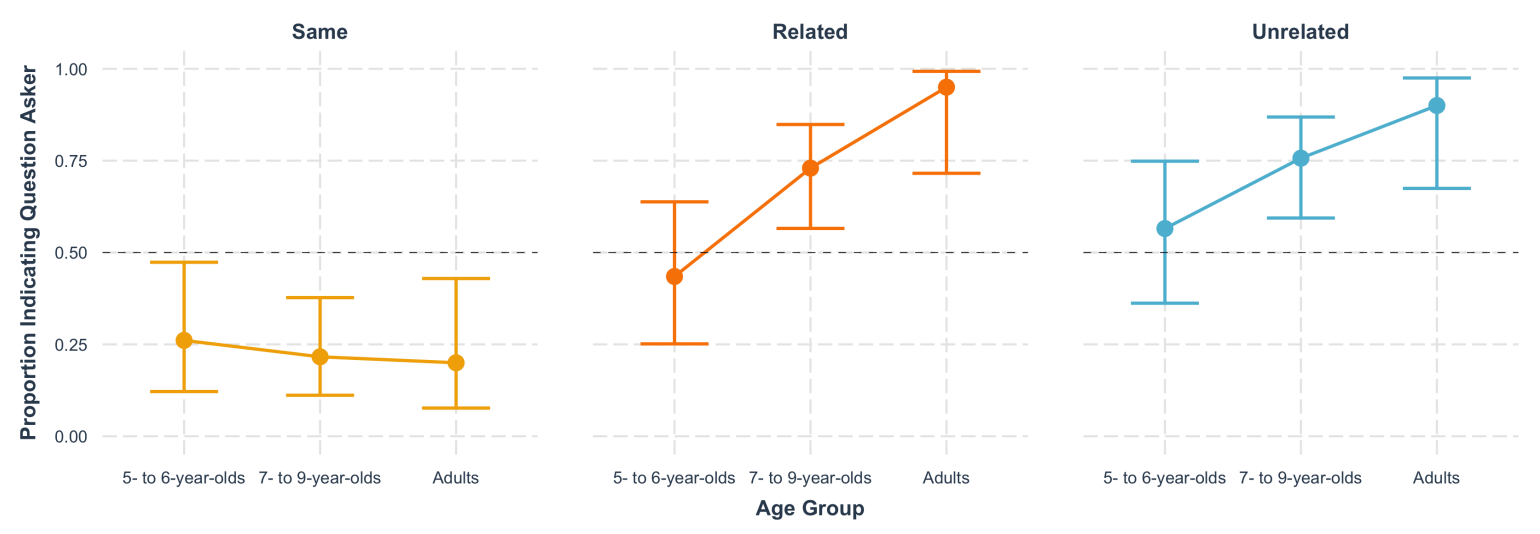

Figure 5. Study 2. Proportion of participants choosing the question asker when they had to ask for help on the three quiz questions, by age group. Dashed horizontal lines represent chance level $(50 \%)$. Bars represent $95 \%$ bootstrapped confidence intervals. Same $=$ the fish domain; related $=$ the animal domain; unrelated $=$ the house domain.

How far do informants' competences generalize? We fit a second mixed-effect logistic regression model predicting participants' attributions of expertise to a subset of the abilities, traits, and characteristics (used in Study $1 \mathrm{a}$ and b) by age (continuous) and their interactions. The 
model revealed that overall, participants were more likely to indicate the question asker when asked which informant was best at treasure hunting $(\beta=1.36, S E=0.43, z=3.16, p=.001)$ or liked ice cream the most $(\beta=0.83, S E=0.36, z=2.28, p=.02)$. No main effect of age nor any interaction effect was found between participants' age and their attribution patterns. Interestingly, as can be seen from Table 3, participants' generalizations were always at chance level: When presented with the informants demonstrating different kinds of expertise (e.g., factual-specific vs. strategic-global), neither adults nor children drew systematic inferences. That is, they made no clear distinctions between knowledgeability and potential for learning.

Table 3

Study 2: Mean Proportion of Participants Who Indicated the Best Question Asker as More Likely to Possess Four Abilities, Traits, and Characteristics

\begin{tabular}{c|ccc|ccc|ccc}
\hline \multirow{2}{*}{ Ability/trait/characteristic } & \multicolumn{3}{|c|}{ 5- to 6-year-olds } & \multicolumn{3}{c|}{ 7- to 9-year-olds } & \multicolumn{3}{c}{ Adults } \\
\cline { 2 - 10 } & $M$ & $95 \%$ CI & $p$ & $M$ & $95 \%$ CI & $p$ & $M$ & 95\% CI & $p$ \\
\hline Being smart & .56 & {$[0.34,0.76]$} & .67 & .35 & {$[0.20,0.52]$} & .09 & .65 & {$[0.40,0.84]$} & .26 \\
Being good at treasure hunting & .65 & {$[0.42,0.83]$} & .21 & .59 & {$[0.42,0.75]$} & .32 & .75 & {$[0.50,0.91]$} & .04 \\
Knowing lots of animal names & .43 & {$[0.23,0.65]$} & .67 & .36 & {$[0.20,0.53]$} & .09 & .30 & {$[0.11,0.54]$} & .11 \\
Liking ice cream & .30 & {$[0.13,0.52]$} & .09 & .59 & {$[0.42,0.75]$} & .32 & .70 & {$[0.45,0.88]$} & .11 \\
\hline
\end{tabular}

Note. $P$ values refer to binomial tests against chance level $(50 \%) . \mathrm{CI}=$ confidence interval. The significance level for all binomial tests was set to $\alpha=.01$ to adjust for the multiple comparisons.

\section{Discussion}

This series of studies was a first attempt to explore what children infer from an agent's ability to ask informative questions. In Study 1 we found an interesting developmental pattern from unsystematic generalization at age 3-4 years, to overgeneralization at age 5-6, to adult-like selective generalization from age 7 onward. The trend found with younger children seems surprising in light of the literature suggesting that even 4-year-olds are already quite good at evaluating the necessary characteristics for being a reliable source of information (e.g., Koenig \& Jaswal, 2011; Kushnir et al., 2013; Sobel \& Corriveau, 2010). Yet, results from studies looking at the extent to which young children generalize informants' traits or knowledge seem to suggest that preschoolers' tendency to draw local rather than global inferences might change depending on several factors, such as the nature and salience of the characteristics or competences 
demonstrated by the informants (e.g., intellectual or physical and episodic or semantic knowledge; see Csibra \& Gergely, 2009; Esbensen et al., 1997) or the extent to which these differences are polarized when presented to children (e.g., see Heyman, Gee, \& Giles, 2003). For example, Fusaro, Corriveau, and Harris (2011) found that 3- and 4-year-olds inferred that a puppet who labeled familiar objects accurately would have been smarter but not stronger or nicer than an inaccurate puppet. They also predicted that the accurate puppet would have been more competent at labeling unknown objects but not at lifting things, sharing cookies, throwing a basketball, or knowing what animals eat, although this last would have been consistent with being smart. Interestingly, when children in this study were presented with two informants differing in physical strength (i.e., successfully or unsuccessfully lifting different items), they made general rather than local attributions. Thus, they inferred that the strong puppet would have been smarter, stronger, and nicer than the weak one, and they also predicted that it would have been more competent in the behaviors listed above (e.g., labeling objects, sharing cookies, or knowing animals' habits; Fusaro et al., 2011). In line with this evidence, we might interpret the trend observed in this study as an indicator of the salience that young children gave to question-asking competence long before their emergent ability to identify or generate effective inquiries (e.g., see Jones, Swaboda, \& Ruggeri, 2020; Ronfard, Zambrana, Hermansen, \& Kelemen, 2018, for reviews). It is plausible that their understanding of this ability is limited to a primarily social function (Graesser, Person, \& Huber, 1992), so that a person asking informative questions is only seen as someone who is friendly and generally sociable and therefore more likely to have grown up with siblings. Evidence supporting this hypothesis is that actually all child participants made the same connection between friendliness and question-asking ability. In support of this account, Heyman and Gelman (1999) found that compared to 5- to 7-year-olds and adults, 4-year-old children tended to rely more on their own or on normative intuitions when making inferences about the motives and feelings of informants that were described as "nice" or "mean." In this sense, although we ensured that participants of all age groups were provided with the same explicit demonstration of what was meant by the definition "good at asking questions," and all 
participants included could reliably identify the "good question asker," it is possible that younger children in our studies held on to their own intuitions about question-asking competence, which may have had nothing to do with their effectiveness and may not have necessarily been reflected in our categories. As an example, our test design admittedly could have included items related to other important and interesting characteristics, such as "sight" and "hearing," which could have also been perceived as related to question-asking competence and would have been suitable for younger children. In this respect, one limitation of this study is that although we know that all the children were familiar with the terms presented, we cannot really be sure about the extent to which they interpreted these terms similarly to adults. For example, the children attending kindergarten ${ }^{7}$ may have thought that "being good at school" meant coloring or drawing well, not throwing tantrums or hitting other children, eating their vegetables, and generally following the rules-rather than achieving good grades, showing a propensity to learn, or reflecting critically on things. Also, they might not have fully appreciated the strategic component underlying the ability to hunt for treasure, which indeed seems to have been more evident to them in the ability to complete jigsaw puzzles. Similarly, they might have struggled to evaluate the ability to find out things as a sign of intelligence, but interestingly, as suggested by their preference response for "knowing many animal names," they linked question-asking competence to being knowledgeable, for instance, about animal names.

Brosseau-Liard and Birch (2010) also suggested that the tendency to draw local rather than global attributions might also be an effect of general age-related experience. In their study, children were presented with an individual's brief history of accuracy in labeling common objects and were asked to make explicit judgments about that individual's future word knowledge as well as broader factual knowledge, talents, or prosocial behavior. Their results show that 4-year-olds do not make the type of explicit attributions that 5-year-olds make, or do so only to a very limited extent, within the same domain as the informants' prior accuracy (i.e., word knowledge). In line

\footnotetext{
${ }^{7}$ All participants aged 3 to 6 years old—except for 2/40 3-year-olds and 8/40 6-year-olds, who had already entered primary school-were enrolled in a kindergarten.
} 
with these findings, other studies have suggested that 5- and 6 year-old children tend to make broad inferences, sometimes even to unrelated domains, when they observe an informant demonstrating specific knowledge (e.g., labeling familiar objects accurately, Brosseau-Liard \& Birch, 2010; knowing causal properties of an object, Sobel \& Corriveau, 2010) or showing sociomoral understanding (Cain, Heyman, \& Walker, 1997). For instance, Rakoczy et al. (2009) found that 5-year-olds deemed an accurate informant (i.e., one who had correctly labeled familiar objects) as more likely than an inaccurate informant to know the rules for a novel game. Moreover, when an informant is presented as possessing epistemic knowledge (e.g., Jaswal \& Malone, 2007; Lane, Wellman, \& Gelman, 2013) and shows prosocial traits (e.g., Heyman \& Gelman, 1999; Liu, Gelman, \& Wellman, 2007), children at this age might be subject to some sort of halo effect that leads them to make global rather than local attributions. On a similar but related note, Gelman and Heyman (1999) showed that 5- and 7-year-old children judged others' characteristics as significantly more stable over time and across contexts when the characteristics were referred to by a noun (i.e., "she is a carrot eater") than when they were referred to by a verbal predicate (i.e., "she eats carrots whenever she can"). In this sense, it is unclear how much of the overgeneralization trend found with 5- to 6-year-olds in Study $1 \mathrm{~b}$ was due to the positive connotation of being "good" versus "bad" at something_in this case at asking questions, or to the fact that the question-asking competence was conveyed as a noun ("The monster is a good question asker") rather than with a verbal predicate ("The monster asks good questions"), or to a genuine appreciation for question-asking competence. This appreciation may be be indirectly reflected in children's selective information seeking. In Study 2 we assessed this possibility by pitting one agent who demonstrated question-asking competence against another agent exhibiting specific domain expertise. In this case, all children and adults identified the knowledgeable expert as the most reliable source of information about the domain that was related to her knowledge. However, when asking for help on broader areas of knowledge, only adults and 7- to 9-year-old children preferred the question asker. In this respect, we could interpret the overgeneralization trend found with 5-year-old children in Study $1 \mathrm{~b}$ as a sort of halo effect resulting from the 
positive valence attributed to the question asker. Similarly, previous work has shown that explicit cues to informants' competence can support younger children's selective information seeking, equating their performance with that of 7-year-olds and adults. In particular, Fitneva and Dunfield (2010) found that 4-year-old children endorsed the accurate informant only when provided with explicit judgments about the informants' ability (i.e., "the informant was very good at answering the question"). Yet, providing children with explicit labels underlining the strengths of the two informants (i.e., "question asker" and "fish expert") did not help 5-year-olds make selective, flexible judgments; that is, they still showed no preference for either of the two informants when seeking assistance to answer the trivia questions. This further supports the idea that children this young may have not yet developed sensitivity to question-asking competence, despite their emergent ability to identify effective questions and queries (e.g., Ruggeri et al., 2017, 2019). The selectivity found with older children in both studies is in line with some of the results obtained in previous studies (e.g., Lane et al., 2013) with this age group. For example, Danovitch and Keil (2007) presented 6-, 8-, and 9-year-olds with four short vignettes illustrating a character facing a moral dilemma (e.g., respecting another's privacy) or involved in a scientific problem (e.g., building a rocket). Following each vignette, participants were asked to choose what characteristics the character would have needed to solve the problem (e.g., if the character needed to be nice to other people or if the character needed to be smart). Their results show that only starting at age 8 did children consistently indicate that scientific skills were necessary to solve scientific problems and that moral characteristics were needed to solve moral dilemmas. It is probably not a coincidence that the ability to make selective, meaningful inferences about question asking seems to emerge at the age when children start becoming more effective at generating questions themselves (Herwig, 1982; Mosher et al., 1966; Ruggeri \& Feufel, 2015). Investigating systematically how children's inferences about question-asking competence relate to their own developing question-asking competence remains an open avenue for future work. In this respect, it would also be interesting to assess if the extent of children's intuitions about question-asking competence would undergo similar developmental trends in the absence of 
explicit labels and/or demonstration of what question-asking effectiveness means. Another exciting idea for future work would be to ask child and adult participants to generate a list of skills/traits/abilities associated with question-asking competence, which could improve external validity.

Finally, in Study 2 we found that neither children nor adults made distinct, consistent inferences from question-asking competence versus knowledgeability. This is not too surprising if one considers that after all, in real life, differentiating the potential for learning from knowledgeability might not always be straightforward. On the one hand, being more knowledgeable might result in developing a high potential for learning. For example, someone who is very knowledgeable might have gained expertise in the process of searching for information, becoming an effective active learner. On the other hand, being an effective active learner might result in being more knowledgeable. Further research is needed to understand whether it is possible to disentangle these two interpretations and their directionality, for example, by exploring whether boosting one aspect will affect the other. Moreover, the impact of motivational factors in such processes should also be addressed, for example, by investigating the possibility that greater motivation to learn might drive the development of active learning strategies, knowledge acquisition, or both.

\section{Conclusion}

To conclude, these findings suggests that across childhood, children get better at recognizing that possessing skills that facilitate knowledge acquisition is crucial for obtaining knowledge that extends beyond the limits of very specific expertise. Overall, this understanding might develop in tandem with the ability to generate effective inquiries, and the underlying categorization and verbal skills (Legare et al., 2013; Ruggeri \& Feufel, 2015).

Future work should investigate this possibility more directly, taking into account the impact of children's inferences and generalizations of question-asking competence on their learning and social behavior, for example, by examining under what conditions and to what extent children prefer to imitate, ask for help, or learn from someone they identify as an effective active learner. 
Ideally, by turning to people who are effective learners and good at asking questions themselves, children might not only effectively learn about the world, but also learn how to learn about the world on their own. 


\section{References}

Agresti, A., \& Min, Y. (2002). On sample size guidelines for teaching inference about the binomial parameter in introductory statistics [unpublished manuscript]. Department of Statistics, University of Florida. Retrieved from www.stat.ufl.edu/aa/articles/ci_proportion.Pdf

Aguiar, N. R., Stoess, C. J., \& Taylor, M. (2012). The development of children's ability to fill the gaps in their knowledge by consulting experts. Child Development, 83(4), 1368-1381. doi: $10.1111 / \mathrm{j} .1467-8624.2012 .01782 . \mathrm{x}$

Bascandziev, I., \& Harris, P. L. (2016). The beautiful and the accurate: Are children's selective trust decisions biased? Journal of Experimental Child Psychology, 152, 92-105. doi: 10.1016/j.jecp.2016.06.017

Bridgers, S., Gweon, H., Bretzke, M., \& Ruggeri, A. (2018). How you learned matters : The process by which others learn informs young children's decisions about whom to ask for help. Cognitive Science, 1, 1402-1407.

Brosseau-Liard, P. E., \& Birch, S. A. (2010). I bet you know more and are nicer too: What children infer from others' accuracy. Developmental Science, 13(5), 772-778. doi: 10.1111/j.1467-7687.2009.00932.x

Brosseau-Liard, P. E., \& Birch, S. A. (2011). Epistemic states and traits: Preschoolers appreciate the differential informativeness of situation-specific and person-specific cues to knowledge. Child Development, 82(6), 1788-1796. doi: 10.1111/j.1467-8624.2011.01662.x

Cain, K. M., Heyman, G. D., \& Walker, M. E. (1997). Preschoolers' ability to make dispositional predictions within and across domains. Social Development, 6(1), 53-75. doi: 10.1111/j.1467-9507.1997.tb00094.x

Campos, J., \& Stenberg, C. (1981). Perception, appraisal, and emotion: The onset of social referencing. Infant social interaction: Empirical and theoretical considerations, pp. 273-314.

Chouinard, M. M., Harris, P. L., \& Maratsos, M. P. (2007). Children's questions: A mechanism 
for cognitive development. Monographs of the Society for Research in Child Development, 72(1), i-179. Retrieved from www. jstor.org/stable/30163594

Csibra, G., \& Gergely, G. (2009). Natural pedagogy. Trends in Cognitive Sciences, 13(4), 148-153. doi: 10.1016/j.tics.2009.01.005

Einav, S., \& Robinson, E. J. (2010). Children's sensitivity to error magnitude when evaluating informants. Cognitive Development, 25(3), 218-232. doi: 10.1016/j.cogdev.2010.04.002

Einav, S., \& Robinson, E. J. (2011). When being right is not enough: four-year-olds distinguish knowledgeable informants from merely accurate informants. Psychological Science, 22(10), 1250-1253. doi: 10.1177/0956797611416998

Esbensen, B. M., Taylor, M., \& Stoess, C. (1997). Children's behavioral understanding of knowledge acquisition. Cognitive Development, 12(1), 53-84. doi: 10.1016/S0885-2014(97)90030-7

Faul, F., Erdfelder, E., Lang, A.-G., \& Buchner, A. (2007). G* power 3: A flexible statistical power analysis program for the social, behavioral, and biomedical sciences. Behavior Research Methods, 39(2), 175-191. doi: 10.3758/BF03193146

Fitneva, S. A., \& Dunfield, K. A. (2010). Selective information seeking after a single encounter. Developmental Psychology, 46(5), 1380-4. doi: https://doi.org/10.1037/a0019818

Fitneva, S. A., Lam, N. H., \& Dunfield, K. A. (2013). The development of children's information gathering: To look or to ask? Developmental Psychology, 49(3), 533-542. doi: $10.1037 / \mathrm{a} 0031326$

Fusaro, M., Corriveau, K. H., \& Harris, P. L. (2011). The good, the strong, and the accurate: Preschoolers' evaluations of informant attributes. Journal of Experimental Child Psychology, 110(4), 561-574. doi: 10.1016/j.jecp.2011.06.008

Gelman, S. A., \& Heyman, G. D. (1999). Carrot-eaters and creature-believers: The effects of lexicalization on children's inferences about social categories. Psychological Science, 10(6), 489-493. doi: https://doi.org/10.1111/1467-9280.00194

Graesser, A. C., Person, N., \& Huber, J. (1992). Mechanisms that generate questions. Questions 
and Information Systems, 2, 167-187.

Herwig, J. E. (1982). Effects of age, stimuli, and category recognition factors in children's inquiry behavior. Journal of Experimental Child Psychology, 33(2), 196-206. doi: $10.1016 / 0022-0965(82) 90015-7$

Heyman, G. D., Gee, C. L., \& Giles, J. W. (2003). Preschool children's reasoning about ability. Child Development, 74(2), 516-534. doi: 10.1111/1467-8624.7402013

Heyman, G. D., \& Gelman, S. A. (1999). The use of trait labels in making psychological inferences. Child Development, 70(3), 604-619. doi: 10.1111/1467-8624.00044.

Jaffer, S., \& Ma, L. (2015). Preschoolers show less trust in physically disabled or obese informants. Frontiers in Psychology, 5, Article 1524. doi: 10.3389/fpsyg.2014.01524

Jaswal, V. K., Croft, A. C., Setia, A. R., \& Cole, C. A. (2010). Young children have a specific, highly robust bias to trust testimony. Psychological Science, 21(10), 1541-1547. doi: $10.1177 / 0956797610383438$

Jaswal, V. K., \& Malone, L. S. (2007). Turning believers into skeptics: 3-year-olds' sensitivity to cues to speaker credibility. Journal of Cognition and Development, 8(3), 263-283. doi: $10.1080 / 15248370701446392$

Jones, A., Swaboda, N., \& Ruggeri, A. (2020). Developmental changes in question-asking. In L. P. Butler, S. Ronfard, \& K. H. Corriveau (Eds.), The questioning child: Insights from psychology and education (pp. 118-143). Cambridge University Press. doi: $10.1017 / 9781108553803.007$

Kachergis, G., Rhodes, M., \& Gureckis, T. (2017). Desirable difficulties during the development of active inquiry skills. Cognition, 166, 407-417. doi: 10.1016/j.cognition.2017.05.021

Kinzler, K. D., Corriveau, K. H., \& Harris, P. L. (2011). Children's selective trust in native-accented speakers. Developmental Science, 14(1), 106-111. doi: 10.1111/j.1467-7687.2010.00965.x.

Kinzler, K. D., \& Spelke, E. S. (2011). Do infants show social preferences for people differing in race? Cognition, 119(1), 1-9. doi: 10.1016/j.cognition.2010.10.019 
Koenig, M. A. (2012). Beyond semantic accuracy: Preschoolers evaluate a speaker's reasons. Child Development, 83(3), 1051-1063. doi: 10.1111/j.1467-8624.2012.01742.x

Koenig, M. A., \& Harris, P. L. (2005). Preschoolers mistrust ignorant and inaccurate speakers. Child Development, 76(6), 1261-1277. doi: 10.1111/j.1467-8624.2005.00849.x

Koenig, M. A., \& Jaswal, V. K. (2011). Characterizing children's expectations about expertise and incompetence: Halo or pitchfork effects? Child Development, 82(5), 1634-1647. doi: 10.1111/j.1467-8624.2011.01618.x

Kominsky, J. F., Langthorne, P., \& Keil, F. C. (2016). The better part of not knowing: Virtuous ignorance. Developmental Psychology, 52(1), 31-45. doi: 10.1037/dev0000065

Kushnir, T., Vredenburgh, C., \& Schneider, L. A. (2013). "Who can help me fix this toy?”: The distinction between causal knowledge and word knowledge guides preschoolers' selective requests for information. Developmental Psychology, 49(3), 446-453. doi: $10.1037 / \mathrm{a} 0031649$

Lane, J. D., Wellman, H. M., \& Gelman, S. A. (2013). Informants' traits weigh heavily in young children's trust in testimony and in their epistemic inferences. Child Development, 84(4), 1253-1268. doi: 10.1111/cdev.12029

Legare, C. H., Mills, C. M., Souza, A. L., Plummer, L. E., \& Yasskin, R. (2013). The use of questions as problem-solving strategies during early childhood. Journal of Experimental Child Psychology, 114(1), 63-76. doi: 10.1016/j.jecp.2012.07.002

Li, Q.-G., Heyman, G. D., Xu, F., \& Lee, K. (2014). Young children's use of honesty as a basis for selective trust. Journal of Experimental Child Psychology, 117, 59-72. doi: 10.1016/j.jecp.2013.09.002

Liu, D., Gelman, S. A., \& Wellman, H. M. (2007). Components of young children's trait understanding: Behavior-to-trait inferences and trait-to-behavior predictions. Child Development, 78(5), 1543-1558. doi: 10.1111/j.1467-8624.2007.01082.x

Lutz, D. J., \& Keil, F. C. (2002). Early understanding of the division of cognitive labor. Child Development, 73(4), 1073-1084. doi: 10.1111/1467-8624.00458 
Ma, L., \& Woolley, J. D. (2013). Young children's sensitivity to speaker gender when learning from others. Journal of Cognition and Development, 14(1), 100-119. doi: $10.1080 / 15248372.2011 .638687$

Mascaro, O., \& Sperber, D. (2009). The moral, epistemic, and mindreading components of children's vigilance towards deception. Cognition, 112(3), 367-380. doi: 10.1016/j.cognition.2009.05.012

Meltzoff, A. N. (1990). Foundations for developing a concept of self. In D. Cicchetti \& B. M. (Eds.), The self in transition: Infancy to childhood (pp. 139-164). Chicago, IL: Chicago University Press.

Mills, C. M. (2013). Knowing when to doubt: Developing a critical stance when learning from others. Developmental Psychology, 49(3), 404-418.

Mosher, F. A., Hornsby, J. R., Bruner, J., \& Oliver, R. (1966). On asking questions. In J. Bruner (Ed.), Studies in cognitive growth (pp. 86-102). New York, NY: Wiley.

Palmquist, C. M., \& Jaswal, V. K. (2015). Preschoolers' inferences about pointers and labelers: The modality matters. Cognitive Development, 35, 178-185.

Pasquini, E. S., Corriveau, K. H., Koenig, M., \& Harris, P. L. (2007). Preschoolers monitor the relative accuracy of informants. Developmental Psychology, 43(5), 1216-1226. doi: 10.1037/0012-1649.43.5.1216

Rakoczy, H., Warneken, F., \& Tomasello, M. (2009). Young children's selective learning of rule games from reliable and unreliable models. Cognitive Development, 24(1), 61-69. doi: 10.1016/j.cogdev.2008.07.004

Robinson, E. J., Butterfill, S. A., \& Nurmsoo, E. (2011). Gaining knowledge via other minds: Children's flexible trust in others as sources of information. British Journal of Developmental Psychology, 29(4), 961-980. doi: 10.1111/j.2044-835X.2011.02036.x

Robinson, E. J., Champion, H., \& Mitchell, P. (1999). Children's ability to infer utterance veracity from speaker informedness. Developmental Psychology, 35(2), 535-546. doi: 10.1037//0012-1649.35.2.535 
Ronfard, S., Zambrana, I. M., Hermansen, T. K., \& Kelemen, D. (2018). Question-asking in childhood: A review of the literature and a framework for understanding its development. Developmental Review, 49, 101-120. doi: 10.1016/j.dr.2018.05.002

Ruggeri, A., \& Feufel, M. (2015). How basic-level objects facilitate question-asking in a categorization task. Frontiers in Psychology, 6, Article 918. doi: 10.3389/fpsyg.2015.00918

Ruggeri, A., \& Lombrozo, T. (2015). Children adapt their questions to achieve efficient search. Cognition, 143(October), 203-216. doi: 10.1016/j.cognition.2015.07.004

Ruggeri, A., Lombrozo, T., Griffiths, T. L., \& Xu, F. (2016). Sources of developmental change in the efficiency of information search. Developmental psychology, 52(12), 2159. doi: $10.1037 / \operatorname{dev} 0000240$

Ruggeri, A., Sim, Z. L., \& Xu, F. (2017). "why is toma late to school again?" preschoolers identify the most informative questions. Developmental Psychology, 53(9), 1620-1632. doi: $10.1037 / \operatorname{dev} 0000340$

Ruggeri, A., Swaboda, N., Sim, Z. L., \& Gopnik, A. (2019). Shake it baby, but only when needed: Preschoolers adapt their exploratory strategies to the information structure of the task. Cognition, 193, Artcile 104013. doi: 10.1016/j.cognition.2019.104013

Sabbagh, M. A., \& Baldwin, D. A. (2001). Learning words from knowledgeable versus ignorant speakers: Links between preschoolers' theory of mind and semantic development. Child Development, 72(4), 1054-1070. doi: 10.1111/1467-8624.00334

Sobel, D. M., \& Corriveau, K. H. (2010). Children monitor individuals' expertise for word learning. Child Development, 81(2), 669-679. doi: 10.1111/j.1467-8624.2009.01422.x

Sobel, D. M., \& Kushnir, T. (2013). Knowledge matters: How children evaluate the reliability of testimony as a process of rational inference. Psychological Review, 120(4), 779-797. doi: $10.1037 / \mathrm{a} 0034191$

VanderBorght, M., \& Jaswal, V. K. (2009). Who knows best? preschoolers sometimes prefer child informants over adult informants. Infant and Child Development, 18(1), 61-79. doi: 
10.1002/icd.591

Zmyj, N., Buttelmann, D., Carpenter, M., \& Daum, M. M. (2010). The reliability of a model influences 14-month-olds' imitation. Journal of Experimental Child Psychology, 106(4), 208-220. doi: 10.1016/j.jecp.2010.03.002 


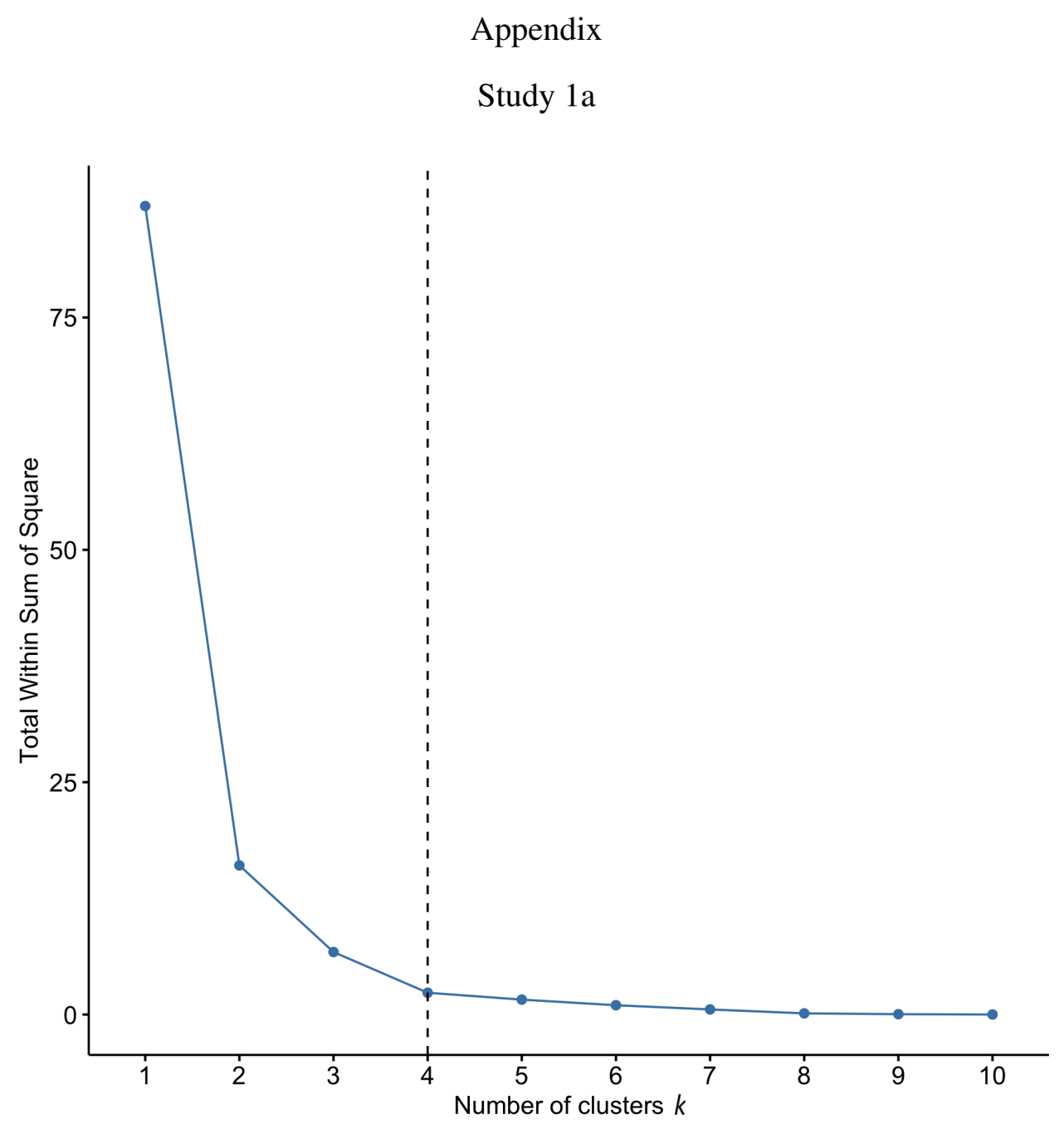

Figure A1. Elbow plot used to determine the optimal number of clusters to retain for hierarchical clustering of questions in Study 1a. With an increase in the number of clusters $(k)$, the average distance between each point in a cluster to its centroid decreases. The optimal number of clusters $(k)$ corresponds to the value of $k$ for which there is a sharp decrease in the distance. 


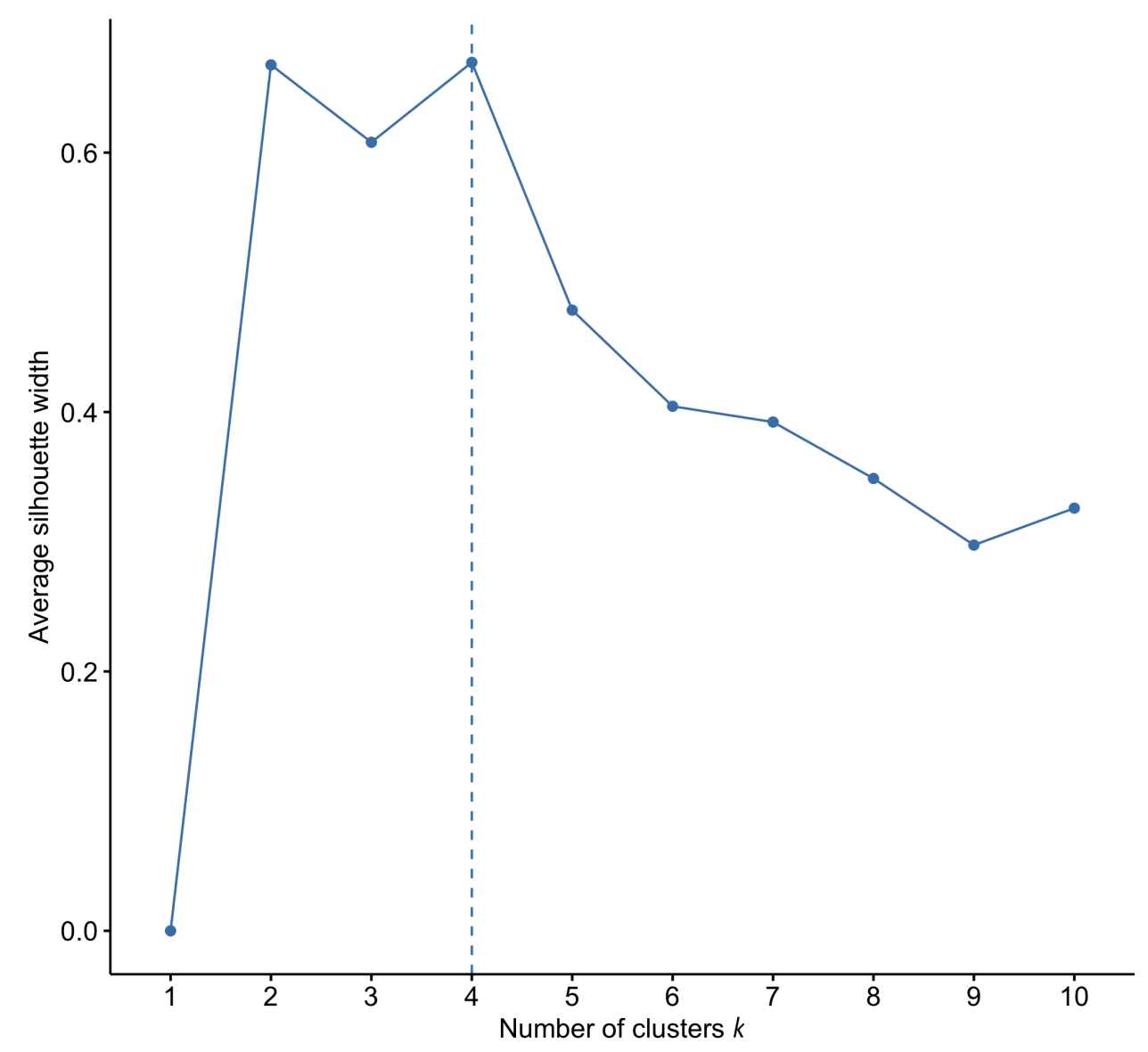

Figure A2. Silhouette plot used to determine the optimal number of clusters to retain for hierarchical clustering of questions in Study 1a. The silhouette width indicates how similar an object is to its own cluster (cohesion) compared to other clusters (separation). The value of the silhouette ranges between 1 and -1 , where a high value indicates that the object is well matched to its own cluster and poorly matched to neighboring clusters. 
Table A1

Distance Matrix Used in the Hierarchical Clustering Process to Evaluate the Dissimilarity Between the 12 Abilities, Traits, and Characteristic Ratings

\begin{tabular}{|c|c|c|c|}
\hline Ability/trait/characteristic & Being smart & Being good at school & Being good at treasure hunting \\
\hline Being smart & 0 & 0.07 & 1.51 \\
\hline Being good at school & 0.07 & 0 & 1.58 \\
\hline Being good at treasure hunting & 1.51 & 1.58 & 0 \\
\hline Being fast at jigsaw puzzles & 2.61 & 2.68 & 1.1 \\
\hline Knowing lots of animal names & 3.84 & 3.91 & 2.33 \\
\hline Being friendly & 4.76 & 4.83 & 3.25 \\
\hline Scoring lots of goals in soccer & 6.81 & 6.88 & 5.3 \\
\hline Being good at playing soccer & 6.54 & 6.61 & 5.03 \\
\hline Having siblings & 6.01 & 6.08 & 4.5 \\
\hline Kicking a ball the farthest & 7.04 & 7.11 & 5.53 \\
\hline Liking ice cream & 7.55 & 7.62 & 6.04 \\
\hline \multirow[t]{2}{*}{ Seeing the farthest } & 6.81 & 6.88 & 5.3 \\
\hline & Being fast at jigsaw puzzles & Knowing lots of animal names & Being friendly \\
\hline Being smart & 2.61 & 3.84 & 4.76 \\
\hline Being good at school & 2.68 & 3.91 & 4.83 \\
\hline Being good at treasure hunting & 1.1 & 2.33 & 3.25 \\
\hline Being fast at jigsaw puzzles & 0 & 1.23 & 2.15 \\
\hline Knowing lots of animal names & 1.23 & 0 & 0.92 \\
\hline Being friendly & 2.15 & 0.92 & 0 \\
\hline Scoring lots of goals in soccer & 4.2 & 2.97 & 2.05 \\
\hline Being good at playing soccer & 3.93 & 2.7 & 1.78 \\
\hline Having siblings & 3.4 & 2.17 & 1.25 \\
\hline Kicking a ball the farthest & 4.43 & 3.2 & 2.28 \\
\hline Liking ice cream & 4.94 & 3.71 & 2.79 \\
\hline \multirow[t]{2}{*}{ Seeing the farthest } & 4.2 & 2.97 & 2.05 \\
\hline & Scoring lots of goals in soccer & Being good at playing soccer & Having siblings \\
\hline Being smart & 6.81 & 6.54 & 6.01 \\
\hline Being good at school & 6.88 & 6.61 & 6.08 \\
\hline Being good at treasure hunting & 5.3 & 5.03 & 4.5 \\
\hline Being fast at jigsaw puzzles & 4.2 & 3.93 & 3.4 \\
\hline Knowing lots of animal names & 2.97 & 2.7 & 2.17 \\
\hline Being friendly & 2.05 & 1.78 & 1.25 \\
\hline Scoring lots of goals in soccer & 0 & 0.27 & 0.8 \\
\hline Being good at playing soccer & 0.27 & 0 & 0.53 \\
\hline Having siblings & 0.8 & 0.53 & 0 \\
\hline Kicking a ball the farthest & 0.23 & 0.5 & 1.03 \\
\hline Liking ice cream & 0.74 & 1.01 & 1.54 \\
\hline \multirow[t]{2}{*}{ Seeing the farthest } & 0 & 0.27 & 0.8 \\
\hline & Kicking a ball the farthest & Liking ice cream & Seeing the farthest \\
\hline Being smart & 7.04 & 7.55 & 6.81 \\
\hline Being good at school & 7.11 & 7.62 & 6.88 \\
\hline Being good at treasure hunting & 5.53 & 6.04 & 5.3 \\
\hline Being fast at jigsaw puzzles & 4.43 & 4.94 & 4.2 \\
\hline Knowing lots of animal names & 3.2 & 3.71 & 2.97 \\
\hline Being friendly & 2.28 & 2.79 & 2.05 \\
\hline Scoring lots of goals in soccer & 0.23 & 0.74 & 0 \\
\hline Being good at playing soccer & 0.5 & 1.01 & 0.27 \\
\hline Having siblings & 1.03 & 1.54 & 0.8 \\
\hline Kicking a ball the farthest & 0 & 0.51 & 0.23 \\
\hline Liking ice cream & 0.51 & 0 & 0.74 \\
\hline Seeing the farthest & 0.23 & 0.74 & 0 \\
\hline
\end{tabular}

Note. Distance was measured with the Minkowski metric, which can be considered a generalization of both the Euclidean distance and the Manhattan distance. 
Table A2

Study 1b: Mixed-Effects Logistic Regression Predicting Children's Learner Choice on Each of 12 Questions by Fixed Effects of Age Group.

\begin{tabular}{|c|c|c|c|c|c|c|c|c|c|c|c|c|}
\hline \multirow[t]{2}{*}{ Predictor } & \multicolumn{4}{|c|}{ Being good at school } & \multicolumn{4}{|c|}{ Being smart } & \multicolumn{4}{|c|}{ Being good at treasure hunting } \\
\hline & OR (Beta) & $S E$ & $Z$ & $p$ & OR (Beta) & $S E$ & $Z$ & $p$ & OR (Beta) & $S E$ & $Z$ & $p$ \\
\hline (Intercept) & $9.00(2.20)$ & 0.53 & 4.17 & .001 & $2.08(0.73)$ & 0.34 & 2.16 & .03 & $3.00(1.10)$ & 0.37 & 3.01 & $<.001$ \\
\hline 3- to 4-year-olds & $0.17(-1.79)$ & 0.62 & -2.9 & $<.001$ & $1.00(-0.00)$ & 0.48 & 0 & 1 & $0.45(-0.80)$ & 0.49 & -1.64 & .01 \\
\hline 5- to 6-year-olds & $0.52(-0.65)$ & 0.67 & -0.96 & .34 & $1.93(0.66)$ & 0.52 & 1.26 & .21 & $0.62(-0.48)$ & 0.49 & -0.97 & .33 \\
\hline \multirow[t]{2}{*}{ 7- to 9-year-olds } & $0.52(-0.65)$ & 0.67 & -0.96 & .34 & $1.66(0.51)$ & 0.51 & 1 & .32 & $0.69(-0.37)$ & 0.5 & -0.74 & .46 \\
\hline & \multicolumn{4}{|c|}{ Being fast at jigsaw puzzles } & \multicolumn{4}{|c|}{ Knowing lots of animals names } & \multicolumn{4}{|c|}{ Being friendly } \\
\hline (Intercept) & $0.54(-0.62)$ & 0.33 & -1.87 & .06 & $1.67(0.51)$ & 0.33 & 1.56 & .12 & $1.00(-0.00)$ & 0.32 & 0 & 1 \\
\hline 3- to 4-year-olds & $3.86(1.35)$ & 0.47 & 2.85 & $<.001$ & $2.07(0.73)$ & 0.5 & 1.45 & .15 & $2.33(0.85)$ & 0.47 & 1.81 & .07 \\
\hline 5- to 6-year-olds & $8.76(2.17)$ & 0.53 & 4.07 & $<.001$ & $2.07(0.73)$ & 0.5 & 1.45 & .15 & $12.33(2.51)$ & 0.68 & 3.7 & $<.001$ \\
\hline \multirow[t]{2}{*}{ 7- to 9-year-olds } & $2.51(0.92)$ & 0.46 & 2 & .05 & $1.80(0.59)$ & 0.49 & 1.2 & .23 & $2.64(0.97)$ & 0.48 & 2.04 & .04 \\
\hline & \multicolumn{4}{|c|}{ Having siblings } & \multicolumn{4}{|c|}{ Being good at playing soccer } & \multicolumn{4}{|c|}{ Seeing the farthest } \\
\hline (Intercept) & $4.71(1.55)$ & 0.42 & 3.73 & .001 & $1.22(0.20)$ & 0.32 & 0.63 & .53 & $1.11(0.10)$ & 0.32 & 0.32 & .75 \\
\hline 3- to 4-year-olds & $0.56(-0.58)$ & 0.55 & -1.06 & .29 & $0.67(-0.40)$ & 0.45 & -0.89 & .37 & $2.71(1.00)$ & 0.48 & 2.07 & .04 \\
\hline 5- to 6-year-olds & $0.39(-0.93)$ & 0.53 & -1.75 & .08 & $2.45(0.90)$ & 0.48 & 1.85 & .06 & $1.88(0.63)$ & 0.46 & 1.36 & .17 \\
\hline \multirow[t]{2}{*}{ 7- to 9-year-olds } & $0.44(-0.82)$ & 0.54 & -1.53 & .13 & $1.70(0.53)$ & 0.46 & 1.14 & .25 & $1.51(0.41)$ & 0.45 & 0.9 & .37 \\
\hline & \multicolumn{4}{|c|}{ Scoring lots of goals in soccer } & \multicolumn{4}{|c|}{ Kicking a ball the farthest } & \multicolumn{4}{|c|}{ Liking ice cream } \\
\hline (Intercept) & $0.43(-0.85)$ & 0.35 & -2.46 & .01 & $1.50(0.41)$ & 0.32 & 1.26 & .21 & $0.67(-0.41)$ & 0.32 & -1.26 & .21 \\
\hline 3- to 4-year-olds & $1.91(0.65)$ & 0.47 & 1.38 & .17 & $1.00(-0.00)$ & 0.46 & 0 & 1 & $1.50(0.41)$ & 0.45 & 0.9 & .37 \\
\hline 5- to 6-year-olds & $2.85(1.05)$ & 0.47 & 2.23 & .03 & $1.00(-0.00)$ & 0.46 & 0 & 1 & $4.50(1.50)$ & 0.49 & 3.09 & $<.001$ \\
\hline 7- to 9-year-olds & $2.85(1.05)$ & 0.47 & 2.23 & .03 & $0.81(-0.20)$ & 0.45 & -0.45 & .65 & $1.50(0.41)$ & 0.45 & 0.90 & .37 \\
\hline
\end{tabular}

Note. Adults' choices are considered as baseline.

Table A3

Study 2: Mixed-Effects Logistic Regression Predicting Children's Learner Choice on Each Question by Age Group.

\begin{tabular}{|c|c|c|c|c|c|c|c|c|c|c|c|c|}
\hline \multirow[t]{2}{*}{ Predictor } & \multicolumn{4}{|c|}{ Same (fish) } & \multicolumn{4}{|c|}{ Related (animals) } & \multicolumn{4}{|c|}{ Unrelated (houses) } \\
\hline & OR (Beta) & $S E$ & $Z$ & $p$ & OR (Beta) & $S E$ & Z & $p$ & OR (Beta) & $S E$ & Z & $p$ \\
\hline (Intercept) & $0.25(-1.39)$ & 0.56 & -2.47 & 0.01 & $19.0(2.94)$ & 1.03 & 2.87 & .001 & $9.00(2.20)$ & 0.75 & 2.95 & .001 \\
\hline 5- to 6-year-olds & $1.41(0.34)$ & 0.73 & 0.47 & 0.64 & $0.04(-3.21)$ & 1.11 & -2.89 & $<.001$ & $0.14(-1.93)$ & 0.86 & -2.26 & 0.02 \\
\hline 7- to 9-year-olds & $1.10(0.10)$ & 0.69 & 0.14 & 0.89 & $0.14(-1.95)$ & 1.09 & -1.79 & 0.07 & $0.35(-1.06)$ & 0.84 & -1.27 & 0.21 \\
\hline
\end{tabular}

